\title{
Reply to the comments of Sokouti et al.: Genitourinary hydatid disease
}

\author{
Savitha Anil Kumar • Archana Shetty • \\ Chowdappa Vijaya $\cdot$ V. Geethamani
}

Received: 1 April 2013/Accepted: 2 April 2013/Published online: 16 May 2013

(C) Springer Science+Business Media Dordrecht 2013

Editor,

At the outset, we appreciate the group of eminent practitioners who have read our article with interest. Regarding the queries raised, we would like to stress on the fact that we have mentioned both in introduction and beginning of the discussion that renal Echinococcosis is primarily caused by the larval form.

Secondary or primary involvement of kidney is through hematogenous spread or through portal system into the liver and retroperitoneal lymphatics by a hydatid embryo (oncosphere) and not by the cyst perse.

Hence, the sentence, "cysts pass through the portal system into the liver and retroperitoneal lymphatics to reach the kidneys" has been overlooked by us as the author of the reference (2) cited by us [Bhandarwar AH, Tayade MB, Makki K, Mhaske S (2009) Primary renal hydatid cyst. Bombay Hosp J 51(3):401-104] has wrongly quoted which we came to know when we retrieved their cross-reference for this point.

We apologize for the same, and we agree that the authors of letter to editor have brought this point to our notice.

We thank you for giving us the opportunity to review the letter to editor, and we request for the correction.

\footnotetext{
S. Anil Kumar $(\varangle) \cdot$ A. Shetty $\cdot$ C. Vijaya

V. Geethamani

Department of Pathology, Sapthagiri Institute of Medical

Sciences and Research Center, Bangalore, Karnataka,

India

e-mail: savitha@kruthika.com
} 